\title{
Application of Seasonal Decomposition on Short-term Forecast of Cigarette sales in Xifeng
}

\author{
Hongmei Zhang ${ }^{1}$ Guangchao Jia $^{1,2}$ Zhe Wang $^{1,2}$ \\ ${ }^{1}$ Guizhou Institute for Urban Economics and Development \\ ${ }^{2}$ School of Finance, Guizhou University of Finance and Economics, Guiyang Guizhou 550025
}

\begin{abstract}
In order to understand future trend of cigarette sales in Xifeng county from the grasp of the macro level, this report completed a short-term prediction for monthly cigarette sales of Xifeng county at year 2011, which based on seasonal decomposition method. To compare with the actual sales, the result shows higher value of application. Also, seasonal decomposition method has obvious maneuverability. For short-term prediction outcome will be much more effective and accurate by applying the method.
\end{abstract}

Keywords:Guiyang, Xi feng, Sales forecast, Seasonal decomposition

\section{Introduction}

Seasonal fluctuations in the time series not only have obvious long-term trend, but also has significant seasonal volatility. The long-term trend is influenced by some factors continuously, so it may be manifested as linear or nonlinear. Seasonal is affected by seasonal climatic, social, customs, etc. exhibit a one-year period, with the passage of the seasons and nature exhibits a certain season occurs each year peak or trough values. Seasonal fluctuations in the complexity of time series variation determines its existence will be difficult to predict. Current solutions to this problem generally include: the seasonal factor decomposition prediction method, Parsons chain proportion method, the fixed base ratio method, Winters linear and seasonal exponential smoothing method, time series decomposition method ${ }^{[1]}$. Among them, the seasonal factor decomposition prediction method can not only consider the trend of seasonal change index, but also make full use of the known data information. Seasonal forecasting decomposition theory is easy to understand, easy to implement on the calculation, therefore, this method is a general method for predicting a better seasonal fluctuations time series.

In recent years, seasonal decomposition method has been widely used to predict prediction research on various economic issues, and achieved fruitful research results. Guo xiuying, etc (2000) in the "seasonal fluctuations time series forecasting seasonal index decomposition method," an article in the study on the basis of the existing prediction methods, proposed a simple, easy to understand and practical prediction method - seasonal index decomposition method, and an example to verify the feasibility of the method $^{[2]}$. In market forecasting, If we ignore the seasonal changes in market demand and make it be generalized treatment, we often lose a lot of valuable information, make observations produce large errors. Yang Jing (2007) used the seasonal factors additive decomposition method to solve this problem in "Application of addition on the seasonal factor decomposition method in market forecast" ${ }^{[3]}$. Seasonal fluctuations in the market for postal savings deposit management is important, one in the fourth quarter of each year is usually the peak season savings, second and third quarter is off-season savings. Xie Ding (2008) proposed residents with Chinese characteristics savings seasonal forecasting methods - incremental prediction method in the " Discussion on Application of household savings seasonal variation prediction method in postal savings ", which took into account the important factor of historical growth, lunar holiday, stock market, interest rate adjustment, has guiding role for the postal savings business management and strategic decision ${ }^{[4]}$.

Currently, in the prediction of the various economic issues, the hot topic is forecasting sales of commodities. Sales forecast refers to estimates of sales volume and sales value of all products or product-specific of a specific time in the future ${ }^{[5]}$. Thus, accurate and reliable sales forecasts for corporate marketing planning is of great importance to safety stock, cash flow and normal operation. This paper will take the Xifeng County of Guizhou province Guiyang city cigarette monthly sales for forecasting object, using seasonal decomposition prediction model for short-term method to build Xifeng cigarette monthly sales. The results show that, using seasonal decomposition method for shortterm sales forecast will get a higher forecasting accuracy.

\section{Xifeng cigarette sales data characteristics}

2008-2011 Xifeng County cigarette monthly sales data, shown in Figure 1. 


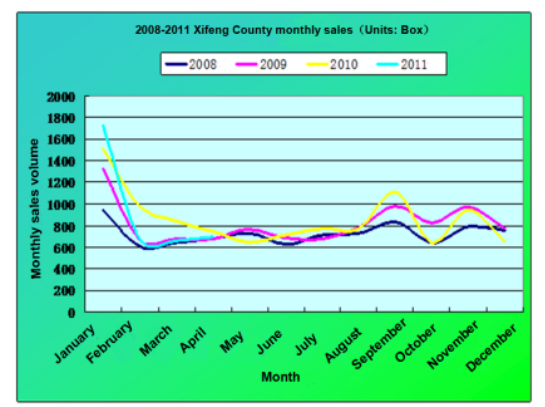

Fig. 1: Degree of 2008-2011 sales years in Xifeng County (Units: Box)

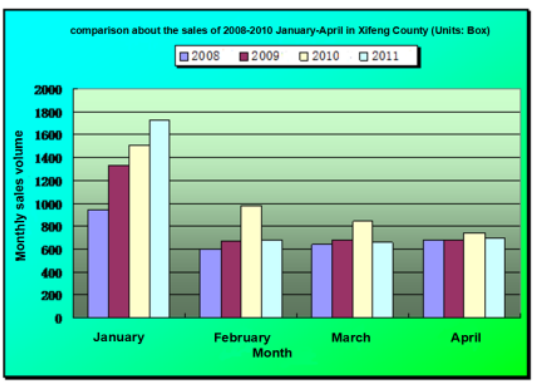

Fig. 2: comparison about the sales of 2008-2010 January-April in Xifeng County (Units: Box)

Figure 1 shows: the county in 2008-2010, cigarette sales in general upward sales trend year by year. Observe the date of the sales data: the highest annual sales in January, reached a peak annual sales, a sharp decline in sales each year in February, to a minimum annual sales. Every year, from March to August, sales showed small fluctuations, changes slightly, sales rose slightly,from September to December sales showed cyclical fluctuations twice, a large variation range, sales increased significantly. Judging that Xifeng County cigarette sales showed some seasonal variation. Xifeng County for 2008-2011 sales from January to April compared in Figure 2. Figure 2 shows: the county in 2008-2011, cigarette sales from January to April show a continued downward trend, cigarette sales in January each year is nearly double the average monthly sales of $2-4$, while cigarette sales each month 2-4 keep downturn, especially in 2011. To eliminate an annual cycle of seasonal fluctuations, according to the 2008-2010 actual sales of cigarettes each month, intends to use the seasonal decomposition prediction method of trying to predict the cigarette sales in 2011 5-8 month.

\section{Xifeng County cigarette sales of short-term forecast}

\subsection{Decomposition season prediction}

Methods of Seasonal forecasting is that change regularly according to the time sequence data presented in the season, to predict the future state of the target ${ }^{[6]}$. Seasonal decomposition prediction is divided into three steps: (1) Separate seasonal component with trend and seasonal factors from the time series; (2) calculated the trend prediction value of the time series with the trend; (3) Using the seasonal index to revise the trend prediction, make the prediction values reflect the trend and seasonal factors ${ }^{[7]}$.

The time series data of Yt $t$ period, it is influenced by the factors of Tt St trend and seasonal factors in the period of T, and of course it has also been influenced by factors during the period of irregular $t$. So the product model of time series of Yt using the following to say:

$$
\mathrm{Yt}=\mathrm{Tt} \times \mathrm{St} \times \mathrm{It}
$$

In the formula(1), $\mathrm{Tt}$ is used to represent the trend of factors predicting unit value. Expressed by seasonal factors influence St or irregular factors of it, when the index is greater than 1, the predicted value will be higher than the trend prediction value. But rather the contrary. Figure 2 shows the sales of the month Xifeng cigarette 2008-2011 years, showed obvious seasonal variation, suitable for using seasonal decomposition prediction method to predict.

\section{2. calculate seasonal index}

Setting seasonal cycle index of 12 , according to the 20082010 actual cigarette sales value of each month, 12-quarter moving average is obtained, the central moving average and seasonal and irregular factors index value. Further calculates the index from January to December season seasonal index and adjust the value of each month after the calculated results are shown in Table 1.

Table.1: adjusted seasonal index from January to December

\begin{tabular}{ccc}
\hline & $\begin{array}{c}\text { Seasonal } \\
\text { Month }\end{array}$ & $\begin{array}{c}\text { Adjusted seasonal } \\
\text { index }\end{array}$ \\
\hline 1 & 1.73 & 1.74 \\
2 & 0.99 & 1.00 \\
3 & 0.91 & 0.92 \\
4 & 0.85 & 0.85 \\
5 & 0.84 & 0.85 \\
6 & 0.83 & 0.83 \\
7 & 0.82 & 0.82 \\
8 & 0.94 & 0.95 \\
9 & 1.11 & 1.12 \\
10 & 0.89 & 0.90 \\
11 & 1.07 & 1.08 \\
12 & 0.94 & 0.94 \\
Sum & 11.92 & 12.00 \\
\hline
\end{tabular}

According to the seasonal decomposition prediction method, time sequence obtained after the seasonal factors, to remove the seasonal factors in time series. Using the seasonal index in Table 1 adjusted, put every time series data of the original value divided by the corresponding 
seasonal index, a new time series obtained can eliminate seasonal factors, makes the product model of the original (1) type into (2) type, so as to get eliminated cigarette monthly sales timeseries after the season factor sequence.

$$
\mathrm{Yt} / \mathrm{St}=\mathrm{Tt} \times \mathrm{St}
$$

\section{3. determine the time series trend}

After the elimination of seasonal time series presents a single linear trend, in order to identify this trend line, the trend to be adopted straight-line method, based on this linear equation:

$$
\mathrm{Tt}=\mathrm{b}+\mathrm{bt}
$$

Of which: $\mathrm{Tt}$ is for the first $\mathrm{t}$ cigarette sales period; as the intercept on the vertical axis of the trend line for the slope of the trend line. The calculation of (3) in the parameter type, using trend equation to eliminate the time series, season after season determined as:

$$
\mathrm{Tt}=816.46+0.66 \mathrm{t}
$$

According to (4), we calculate the value of the monthly

\begin{tabular}{|c|c|}
\hline Year 2011 & $\begin{array}{c}\text { Trend prediction } \\
\text { value }\end{array}$ \\
\hline January & 843.71 \\
\hline February & 844.38 \\
\hline March & 845.04 \\
\hline April & 845.71 \\
\hline May & 846.37 \\
\hline June & 847.04 \\
\hline July & 847.70 \\
\hline August & 848.37 \\
\hline September & 843.71 \\
\hline October & 844.38 \\
\hline November & 845.04 \\
\hline December & 845.71 \\
\hline
\end{tabular}
forecast 2011 sales of cigarettes each month, see Table 2.

Table.2: Monthly sales forecasts

\subsection{The predictive value of seasonal adjustment}

In order to make the 2011 monthly sales forecast value more precise, according to the seasonal index after the adjustment, the predicted values were adjusted to table 2 . The adjusted predicted values are shown in table 3 . The 1-4 month for the actual cigarette sales value, 5-12 months to predict cigarette sales value. According to table 3, drawing the 2011 Annual Xifeng cigarette sales trend, see in figure 3.
Table.3: Predictive value of adjustment

\begin{tabular}{cccc}
\hline $\begin{array}{c}\text { 2011 } \\
\text { Month }\end{array}$ & $\begin{array}{c}\text { Trend } \\
\text { prediction } \\
\text { value }\end{array}$ & $\begin{array}{c}\text { The } \\
\text { seasonal } \\
\text { index }\end{array}$ & $\begin{array}{c}\text { Adjusted } \\
\text { prediction } \\
\text { value }\end{array}$ \\
\hline 1 & 843.71 & 1.74 & 1727.01 \\
2 & 844.38 & 1.00 & 677.39 \\
3 & 845.04 & 0.92 & 654.80 \\
4 & 845.71 & 0.85 & 691.14 \\
5 & 846.37 & 0.85 & 715.58 \\
6 & 847.04 & 0.83 & 704.47 \\
7 & 847.70 & 0.82 & 695.97 \\
8 & 848.37 & 0.95 & 801.12 \\
9 & 843.71 & 1.12 & 943.94 \\
10 & 844.38 & 0.90 & 761.91 \\
11 & 845.04 & 1.08 & 915.74 \\
12 & 845.71 & 0.94 & 799.01 \\
\hline
\end{tabular}

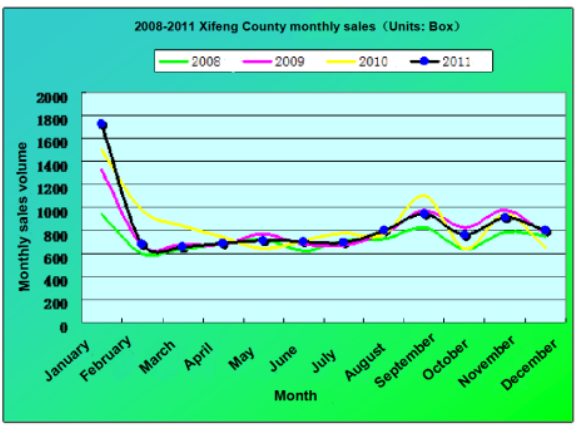

Fig.3: The trends of 2011 annual cigarette sales in Xifeng County

In Figure 3, the black line for cigarette sales forecast 2011 1-4 month and 5-12 months value actual value trend prediction curve, the linear trend with 2008-2010 years of linear trend of the basic anastomosis. It shows the seasonal decomposition prediction method is more objective and accurate reflection of Xifeng County in 2011 full year cigarette sales situation, in the range of allowable error, the prediction results show that: (1) the total amount of sales of 2011 year in Xifeng County is 10088.08 box, slightly lower than 10299.98 box in 2010 , compared with the previous year, cigarette sales will be reduced by about 211.90 boxes; (2)the county's cigarette sales will continue to maintain the slumping sales situation in $20112-8$ months; two periodic fluctuation will appear 9-12 months, the change amplitude will significantly stimulate the sales.

\section{Conclusion}

Continue to carry on the forecast to the 2012 January Xifeng county cigarette sales, sales of the month is 1561.636 boxes. It is visible that sales data in January of each year have certain differences. There are three reasons that every year January sales promotion: one is because of seasonal variation, January is the traditional folk festival, the number of people buying cigarettes as gifts increases; 
the two is a large number of migrant workers return home, Having the Spring Festival at home; three is the tobacco industry administrative intervention in the market results. The empirical analysis shows that: using seasonal decomposition method for sales forecasting, the prediction accuracy is higher , at the same time, the prediction has higher practical application value. But the seasonal decomposition method is relatively simple, in order to improve the forecasting accuracy of short-term sales, considering the combination forecasting of seasonal fluctuations in time series, such methods need to be further research in the future.

\section{Acknowledgments}

Thanks to the tobacco companies in Guizhou Province Guiyang City Marketing Center Marketing Department on this project support.

\section{References}

[1] G. X. Xu,Statistical forecasting and decision-making [M],Shanghai: Shanghai Finance University Press,2008.

[2] X. Y. Guo, X. G. Yin. etc, "Seasonal fluctuations in the decomposition of seasonal time series forecasting index method," Proc. Mathematical Statistics and Management, pp. 60-64, 2000(6).

[3] J. Yang, "On an additive decomposition seasonal factors in the market prediction," Proc. Research World, pp. 37-38, 2007(12).

[4] D. Xie, "Seasonal changes in household savings in the postal savings forecasting methods in the application," Proc. Postal Studies, pp. 5-6, 2008(2).

[5] John T, Mentzer,Carol C. Bienstock. Sales forecasting (Method system management) [M],Beijing: People's Posts and Telecommunications Press, 2004.

[6] S. F. Liu, Yao-party state. Prediction methods and techniques [M], Beijing: Higher Education Press, 2005.

[7] B. T. Han, Management Operations Research [M], Beijing: Higher Education Press, 2005. 